\title{
Preparation and Characterization of Nickel Ferrite Nanoparticles via Sol-gel Method
}

\author{
Savithri. M. Nampoothiri ${ }^{1}{ }^{*}$, Viji. C$^{1}$, E. M. Mohammed', Robin Francis ${ }^{1}$ \\ ${ }^{1}$ Department of Physics, Maharaja's College, Mahatma Gandhi University, Ernakulam, 682011, India
}

*Corresponding author: E-mail: cmsavithrinampoothiri@gmail.com; Tel: (+91) 9495878273

DOI: 10.5185/amlett.2020.021473

Nickel ferrite $\left(\mathrm{NiFe}_{2} \mathrm{O}_{4}\right)$ nanoparticles were synthesized using sol-gel method and the powdered samples were sintered at $100^{\circ} \mathrm{C}$ and $200^{\circ} \mathrm{C}$. X-ray Diffraction (XRD) patterns were used to determine the structure of nickel ferrite nanoparticles. Obtained the lattice parameter from the XRD data and calculated the particle size using Debye- Sherrer formula. The details of the surface morphology of $\mathrm{NiFe}_{2} \mathrm{O}_{4}$ nanoparticles were studied by Scanning Electron Microscopic (SEM) analysis. The work aims at the investigation of the dielectric properties such as dielectric loss and permittivity of Nickel ferrite nanoparticles at various frequencies and temperatures. In addition, the ac conductivity of the nickel ferrite nanoparticles was studied.

\section{Introduction}

Material science is a field that is evolving at a very fast pace and is currently making the most significant contributions to Nano scale research. Because of the several potential applications, nanomaterials and nanostructures have a great deal of attention in areas such as electronics, optics, catalysis, ceramics, information storage, medicine, and health care.

Nanomaterials are those whose characteristic length scale lies within the range between 1 and $100 \mathrm{~nm}$. They often display characteristic properties intermediate between quantum and bulk materials. Since the evolution of life on earth, nanostructured organic, inorganic and biological materials have existed in nature. Some evident examples are microorganisms, fine grained minerals in rocks, nanoparticles in bacteria and smoke [1]. Among many known nanomaterials, magnetic nanomaterials and nanostructures have a special position because of their important technological and biomedical applications. In the last 50years magnetic nanoparticle has been the main subject of study since the pioneering work of Louis Neel. Magnetic nanoparticles exhibit the unique phenomena such as superparamagnetism [2] and quantum tunneling of magnetization [3]. Polycrystalline Ferrites are the most widely used oxide magnetic nanomaterial. Generally, ferrites are denoted by the chemical formula $\mathrm{MO} . \mathrm{Fe}_{2} \mathrm{O}_{3}$ where $\mathrm{M}$ is a divalent metal ion such as $\mathrm{Mn}^{2+}, \mathrm{Fe}^{2+}, \mathrm{Co}^{2+}$, $\mathrm{Ni}^{2+}, \mathrm{Cu}^{2+}, \mathrm{Zn}^{2+}, \mathrm{Mg}^{2+}$ or $\mathrm{Cd}^{2+}$. The word ferrite is derived from the Latin word "Ferrum" meaning iron and was first used at the beginning of $20^{\text {th }}$ century [4]. Nano-crystalline spinel ferrites have been the technologically important material over the past several years due to their functional electrical and magnetic properties. These types of ferrites exhibit high thermodynamic stability, high electrical conductivity and high corrosion resistance [5]. Ferrites have a variety of promising technological applications such as ferrofluids, high density magnetic recording media and magnetic fluids for storage and retrieval of information, color imaging and magnetic resonance imaging (MRI) enhancement, catalysis, magnetically guided drug delivery, sensors and pigments [5]. Nickel ferrites are one of the multifaceted soft ferrite materials due to their typical ferromagnetic properties, lower eddy current losses, low conductivity, and high electrochemical stability [6]. These are the promising materials for use in telecommunication equipment, computer peripherals, and other electronics and microwave devices. Magnetic properties of Nickel ferrite and other ferrites depend on the type of cations and their distribution between tetrahedral and octahedral positions [5]. Nickel ferrite adopts an inverse spinel structure with $\mathrm{Ni}^{2+}$ in octahedral sites and $\mathrm{Fe}^{3+}$ in the space equally distributed between octahedral and tetrahedral sites. However, nickel ferrite shows superparamagnetic nature and it has diverse applications as gas-sensors, magnetic fluids, catalysts, magnetic storage systems, photo-magnetic materials, sitespecific drug delivery systems, magnetic resonance imaging systems, and microwave devices [6]. Despite the wide-spread application of nickel ferrite nanoparticles, there is a serious lack of information concerning the toxicity of these nanoparticles at the cellular and molecular level. A few significant studies have reported potential cytotoxicity of spinel ferrite nanoparticles including Nickel ferrite nanoparticles [7-10]. Nickel ferrite nanoparticles show only minimal changes on HeLa cell proliferation at concentrations of $10 \mathrm{~g} / \mathrm{ml}$, but significantly low viability at concentrations of $100 \mathrm{~g} / \mathrm{ml}$ [10]. Various methods such as hydrothermal method, co-precipitation method, sol-gel method, thermolysis, wet chemical coprecipitation technique etc. have been developed to prepare nanocrystalline nickel ferrite. This paper is on the synthesis of $\mathrm{NiFe}_{2} \mathrm{O}_{4}$ nanoparticles using sol-gel method, their characterization using powder X-ray diffraction and SEM and the determination of their dielectric properties. 


\section{Advanced}

\section{Experimental}

For the preparation of nanoparticles, stoichiometric ratios of AR grade Ferric nitrate $\left(\mathrm{Fe}\left(\mathrm{NO}_{3}\right)_{3} .9 \mathrm{H}_{2} \mathrm{O}\right)$ and Nickel nitrate $\left(\mathrm{Ni}\left(\mathrm{NO}_{3}\right)_{2} .6 \mathrm{H}_{2} \mathrm{O}\right)$ were dissolved in a minimum amount of ethylene glycol at room temperature. The solution is then heated at $60^{\circ} \mathrm{C}$ to form a wet gel. Then the gel was dried at $120^{\circ} \mathrm{C}$ for $2 \mathrm{hrs}$ and as a result of which, the gel was self-ignited to form $\mathrm{NiFe}_{2} \mathrm{O}_{4}$ powder. The combustion can be taken as a thermally induced redox reaction of the gel wherein ethylene glycol acts as a reducing agent and the nitrate ion acts as an oxidant. The nitrate ion provides an in situ oxidizing environment for the decomposition of the organic component. The product obtained was then ground well and the two portions were sintered for 2 hours in a muffle furnace at $100^{\circ} \mathrm{C}$, and $200^{\circ} \mathrm{C}$ respectively.

\section{Characterization}

XRD spectra of $\mathrm{NiFe}_{2} \mathrm{O}_{4}$ nanoparticles were taken at room temperature in the range 2 theta $=20-80^{\circ}$ on a Rigaku Mini Flex 600 using $\mathrm{Cu} \mathrm{K} \alpha$ radiation $\left(\mathrm{k}=1.5406 \mathrm{~A}^{\circ}\right)$. SEM of the $\mathrm{NiFe}_{2} \mathrm{O}_{4}$ composite was recorded using TESCAN VEGA 3 SBH microscope. The dielectric properties of $\mathrm{NiFe}_{2} \mathrm{O}_{4}$ nanoparticles were analyzed using a Wayne Kerr $6500 \mathrm{~B}$ over the frequency range $100 \mathrm{~Hz}$ $120 \mathrm{MHz}$. The $\mathrm{NiFe}_{2} \mathrm{O}_{4}$ nanoparticle pellets in disc form were studied at two different temperatures. For measurements, a sample was placed between copper platforms and electrodes. The capacitance and dissipation factor of the parallel plate capacitor formed by the copper plate and the electrode having the sample as a dielectric medium were measured.

\section{Results and discussion}

\section{XRD analysis}

Fig. 1 and Fig. 2 shows the XRD patterns of the prepared $\mathrm{NiFe}_{2} \mathrm{O}_{4}$ nanoparticles. The patterns were compared with standard data (JCPDS PDF card No.074-2081) and the formation of single phase cubic $\mathrm{NiFe}_{2} \mathrm{O}_{4}$ nanoparticles in all the samples was confirmed. Crystalline sizes of the samples were calculated using Debye-Scherrer formula.

$$
\mathrm{D}=\frac{0.9 * \lambda}{\beta \cos \theta}
$$

where $\lambda$ is the $\mathrm{X}$-ray wavelength $(\mathrm{CuK} \alpha$ radiation and equals to $0.154 \mathrm{~nm}), \theta$ is the Bragg diffraction angle, and $\beta$ is the FWHM of the XRD peak appearing at the diffraction angle $\theta$.

The crystalline size was observed to increase with temperature. The average crystalline size was calculated from the X-ray line broadening using Scherrer equation and it was found to be about $15.53 \mathrm{~nm}$ and $17.14 \mathrm{~nm}$ for $100{ }^{\circ} \mathrm{C}$ and $200{ }^{\circ} \mathrm{C}$ respectively. Calculated values of lattice parameter of Nickel ferrite samples are listed in Table 1 and Table 2 which are in close agreement with standard data. It is clear from the table that the lattice constant is almost constant and shows only negligible variation with sintering temperature. But the size of the nanoparticles increases with sintering temperature.

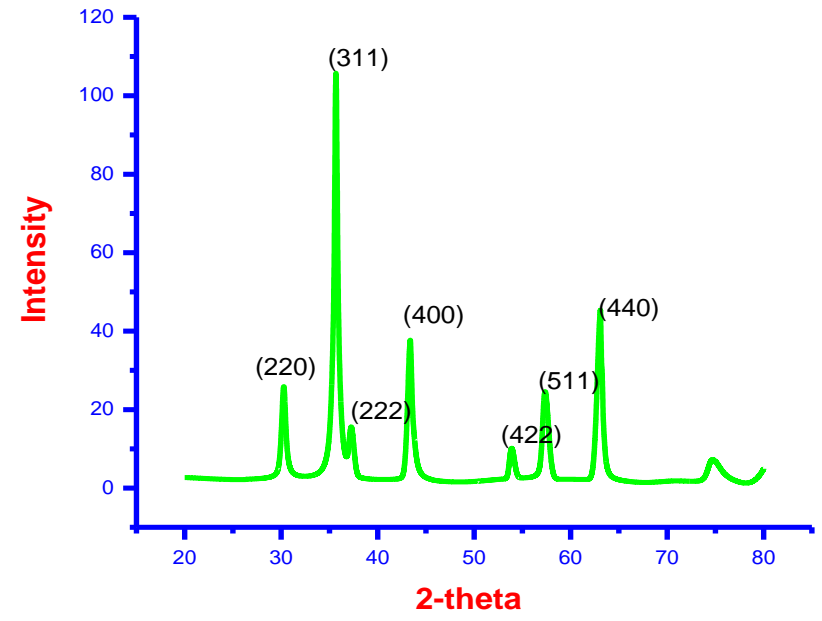

Fig. 1. $\mathrm{NiFe}_{2} \mathrm{O}_{4}$ at $100^{\circ} \mathrm{C}$.

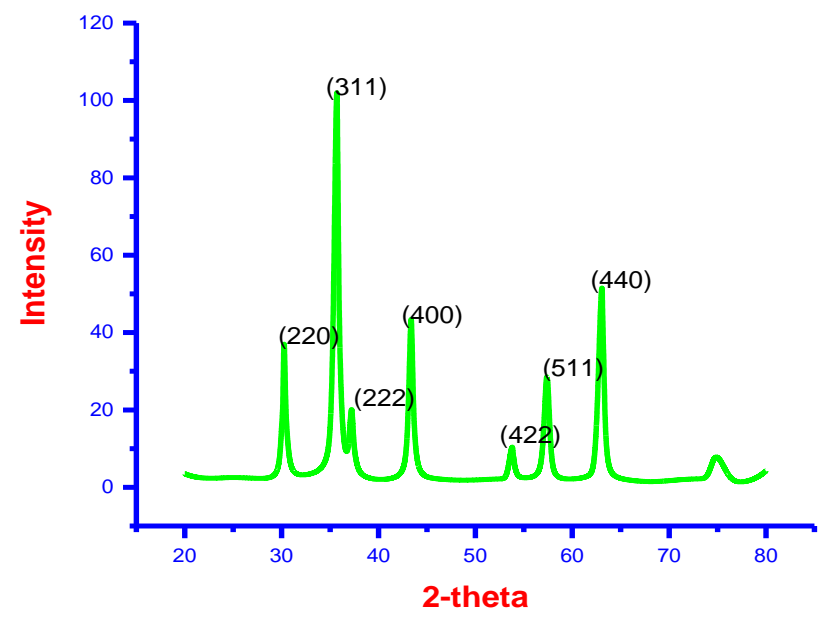

Fig. 2. $\mathrm{NiFe}_{2} \mathrm{O}_{4}$ at $200^{\circ} \mathrm{C}$.

Table 1. Particle size and Lattice parameter of $\mathrm{NiFe}_{2} \mathrm{O}_{4}$ nanoparticle at $100^{\circ} \mathrm{C}$.

\begin{tabular}{c|c|c|c|c|c}
\hline $\begin{array}{c}\text { 2- } \\
\text { Theta }\end{array}$ & FWHM & $\begin{array}{c}\text { Particle } \\
\text { size D } \\
(\mathbf{n m})\end{array}$ & $\begin{array}{c}\text { Average } \\
\text { particle } \\
\text { size }\end{array}$ & $\begin{array}{c}\text { Inter } \\
\text { planar } \\
\text { spacing } \\
\mathbf{d}\left(\mathbf{A}^{\circ}\right)\end{array}$ & $\begin{array}{c}\text { Lattice } \\
\text { constant } \\
\mathbf{a}\end{array}$ \\
\hline 30.25 & 0.49 & 16.8077 & 15.5316 & 2.9544 & 8.3565 \\
\hline 35.64 & 0.59 & 14.1544 & & 2.5190 & 8.3547 \\
\hline 37.23 & 0.56 & 14.981 & & 2.4150 & 8.3659 \\
\hline 43.38 & 0.52 & 16.4544 & & 2.0858 & 8.4342 \\
\hline 53.82 & 0.56 & 15.9212 & & 1.7033 & 8.3444 \\
\hline 57.26 & 0.69 & 13.1275 & & 1.6088 & 8.3600 \\
\hline 63.08 & 0.54 & 17.2750 & & 1.4737 & 8.3366 \\
\hline
\end{tabular}

Table 2. Particle size and Lattice parameter of $\mathrm{NiFe}_{2} \mathrm{O}_{4}$ nanoparticle at $200^{\circ} \mathrm{C}$.

\begin{tabular}{c|l|c|c|c|c}
\hline $\begin{array}{c}\text { 2- } \\
\text { Theta }\end{array}$ & $\begin{array}{l}\text { FWH } \\
\mathbf{M}\end{array}$ & $\begin{array}{c}\text { Particle } \\
\text { size D } \\
(\mathbf{n m})\end{array}$ & $\begin{array}{c}\text { Average } \\
\text { particle } \\
\text { size }\end{array}$ & $\begin{array}{c}\text { Inter } \\
\text { planar } \\
\text { spacing } \\
\mathbf{d}\left(\mathbf{A}^{\circ}\right)\end{array}$ & $\begin{array}{c}\text { Lattice } \\
\text { constant } \\
\mathbf{a}\end{array}$ \\
\hline 30.22 & 0.43 & 19.1516 & 17.148 & 2.9535 & 8.3383 \\
\hline 35.69 & 0.52 & 16.0621 & & 2.5149 & 8.3411 \\
\hline 37.21 & 0.47 & 17.5457 & & 2.4156 & 8.3681 \\
\hline 43.36 & 0.47 & 18.2036 & & 2.0858 & 8.3434 \\
\hline 53.81 & 0.50 & 18.1263 & & 1.6058 & 8.3440 \\
\hline 57.35 & 0.60 & 15.1031 & & 1.4741 & 8.3390 \\
\hline
\end{tabular}




\section{Advanced Materials Letters www. vbripress.com/aml}

\section{Dielectric properties}

It is usually observed that dielectric data are regarded as the combination of two progressions, a conductivity involvement that results in an increase of both real part $\boldsymbol{\varepsilon}_{\mathrm{r}}$ and imaginary part $\boldsymbol{\varepsilon}^{\prime \prime}$ of the dielectric function on lessening frequency and a relaxation contribution showing a maximum in $\boldsymbol{\varepsilon}^{\prime \prime}$ that changes upper frequency part with rise in temperature. Frequency dependence of the dielectric constant and dielectric loss at various temperatures is shown in Fig. 3 and Fig. 4 respectively.

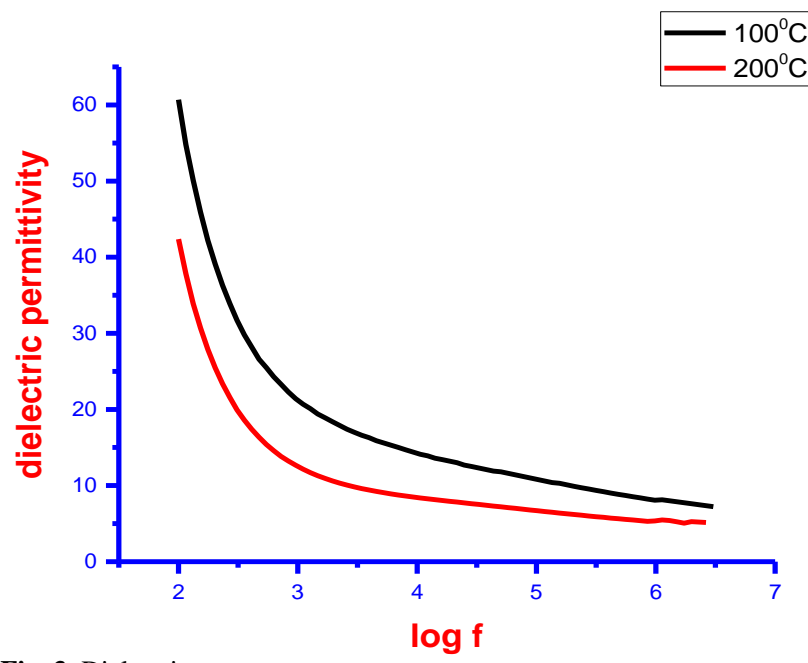

Fig. 3. Dielectric constant.

From Fig. 3 it is clear that the dielectric constant initially decreases rapidly with increase in frequency and then slowly at higher frequencies. Greater values of dielectric constant at lower frequency values are possible due to the charge accumulation at the grain boundaries. The decrease in dielectric constant with frequency is a normal dielectric behavior of soft ferrites. The frequency variation of dielectric constant reveals the dispersion due to Maxwell-Wagner type [11] interfacial polarization, which is in agreement with Koop's phenomenological theory [12]. According to this model, the dielectric structure of the ferrite is supposed to be composed of two layers; well conducting grains which are separated by poorly conducting grain boundaries. The grain boundaries are more effective at low frequencies, but grains are effective at high frequencies [12].

In ferrites, the mechanism of electric conduction and dielectric polarization are similar [13]. In $\mathrm{NiFe}_{2} \mathrm{O}_{4}$ electrical conduction is facilitated through hopping of electrons between $\mathrm{Fe}^{2+}$ and $\mathrm{Fe}^{3+}$ ions and hopping of holes between $\mathrm{Ni}^{3+}$ and $\mathrm{Ni}^{2+}$ ions on octahedral sites and give local displacements of electrons in the direction of applied field and that results in polarization. During hopping process, electron must pass through grains and grain boundaries of the medium. Grain boundaries have high resistance so that electrons get accumulated on the grain boundaries and produce space charge polarization which results in high value of dielectric constant at low frequencies [14]. At high frequencies, dielectric constant is very small because the conductivity is high; hopping of electrons cannot follow the alternating field. In this work, it is observed that dielectric constant is reduced with the increase in sintering temperature, because the resistivity of the sample is enhanced with increase in temperature.

Energy absorption within a dielectric medium is characterized by the loss factor $\tan \delta$. Fig. 4 shows that tan $\delta$ decreases with frequency. As frequency increases, the rate of decrease slows down and the loss factor becomes almost frequency independent. Due to the high resistivity at the grain boundaries, the value of loss factor is high at lower frequencies. Hence more energy is required for hopping process, resulting in high energy loss. However, in the high frequency region, due to the high conductivity of grains, energy required for hopping is less and hence small loss factor.

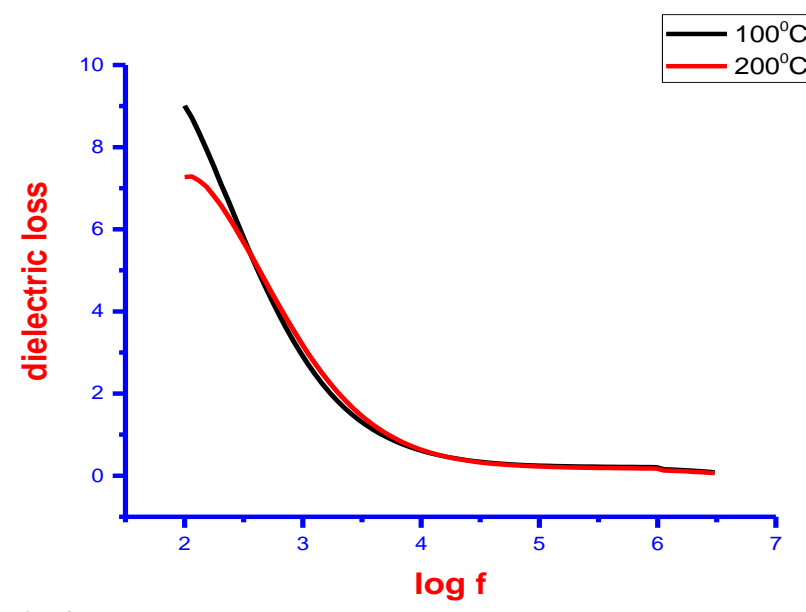

Fig. 4. Dielectric loss.

\section{AC conductivity}

The ac conductivity of the samples was calculated from the dielectric data using the equation:

$$
\sigma_{a c}=2 \pi f \epsilon_{0} \varepsilon_{r} \tan \delta
$$

The variations of ac conductivity as a function of frequency for the synthesized $\mathrm{Ni}$-ferrite samples are shown in Fig. 5.

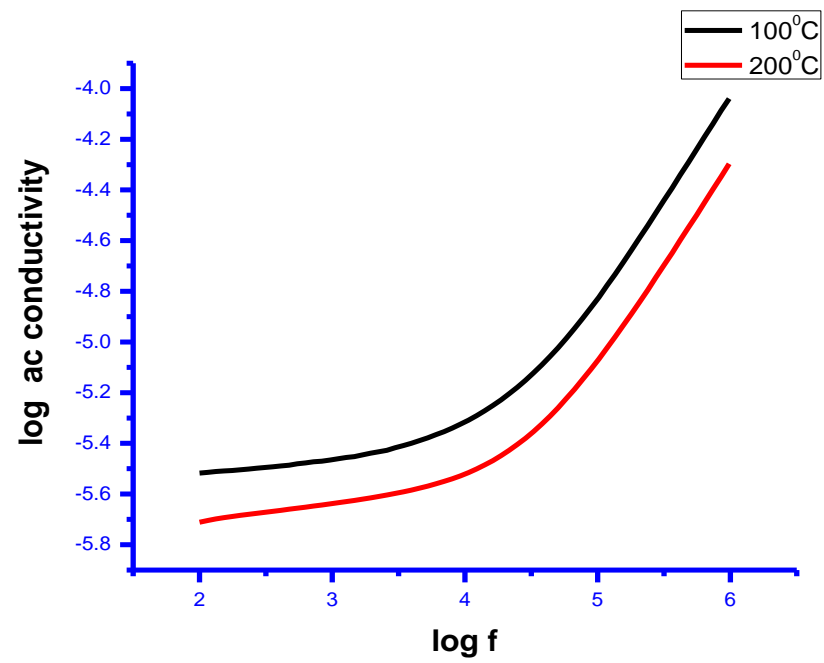

Fig. 5. Variation of ac conductivity with frequency. 


\section{Advanced Materials Letters www. vbripress.com/aml}

It is clear that conductivity is almost constant in the low frequency region and at high frequencies, plots are observed to be linear, confirming the small polaron type conduction in the samples. Small polaron formation may be due to the defects or oxygen vacancies created during sintering. In most of the disordered solids ac conductivity is directly proportional to the frequency, confirming the linear nature [15]. It is observed that ac conductivity increases gradually with increased frequency. Since the increase in frequency enhances electron hopping frequency, conductivity increases. The frequency dependence of ac conductivity can be explained with the help of Maxwell-Wagner [13] two-layer model of polycrystalline ferrites. When the applied frequency is low, poorly conducting grain boundaries are more effective and so conductivity is less. As the frequency rises, conductive grains become active and hence hopping conduction increases. It is also evident from Fig. 5 that conductivity is lowered by the increase in sintering temperature.

\section{SEM analysis}

The samples needed a coating of gold-palladium for SEM analysis for avoiding of charging effect. The morphology and the size distribution of the $\mathrm{NiFe}_{2} \mathrm{O}_{4}$ nanoparticles were determined using SEM. Typical SEM images of $\mathrm{NiFe}_{2} \mathrm{O}_{4}$ synthesized particles are shown in Fig. 6 and Fig. 7. SEM micrograph depicts micrometrical aggregation of tiny particles. The existence of high dense agglomeration indicates that pore free crystallites are present on the surface. As the nanoparticles possess high surface energies, they tend to agglomerate and grow into larger assemblies.

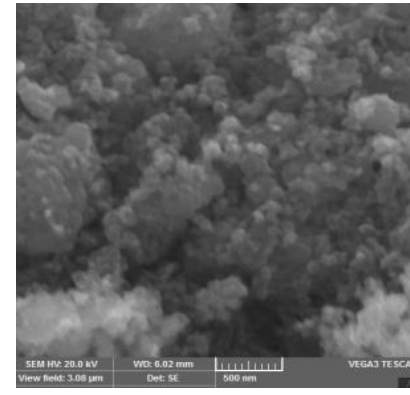

Fig. 6. $\mathrm{NiFe}_{2} \mathrm{O}_{4}$ at $100^{\circ} \mathrm{C}$.

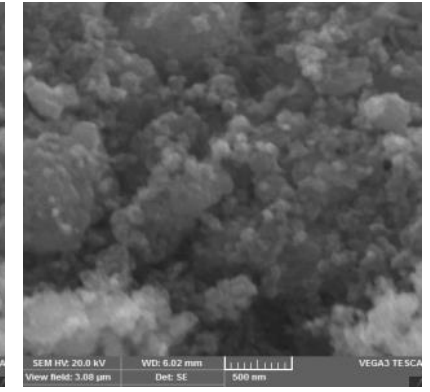

Fig. 7. $\mathrm{NiFe}_{2} \mathrm{O}_{4}$ at $200^{\circ} \mathrm{C}$.

\section{Conclusion}

Nano-crystalline Nickel ferrite was synthesized by sol-gel method. Cubic spinel structure of Nickel ferrite was established by XRD. The average particle size of the samples was calculated using Sherrer formula and it was found to be $15 \mathrm{~nm}$ and $17 \mathrm{~nm}$ for samples sintered at $100^{\circ} \mathrm{C}$ and $200^{\circ} \mathrm{C}$ respectively. That the nanoparticle agglomerated to form spherical-shaped particles was also confirmed by the SEM analysis. The impact of frequency and the temperature on the dielectric constant and the dielectric loss for Nickel ferrite samples were studied. And also variation of ac conductivity with frequency was studied. From the dielectric studies it is clear that frequency has a negative impact on both dielectric loss and dielectric constant as it decreases with increase in frequency.

\section{Acknowledgements}

The authors gratefully acknowledge The Kerala State Council for Science, Technology and Environment (KSCSTE), Kerala, India for the financial support. We thank the Head of the Department of Physics and the Principal, Maharaja's College, Ernakulam and Dr. Tina Sebastian, Deva Matha College, Kuravilangad for extending the facilities for this work.

\section{Keywords}

Nickel ferrite nanoparticles, XRD, SEM, Dielectric loss, permittivity, AC conductivity.

\section{Received: 25 June2019}

Revised: 07 August 2019

Accepted: 23 October 2019

\section{References}

1. Nalwa, H.S.; "Nanostructure Materials \& Nanotechnology", Concise Editition San-Diego, 2002.

2. Bean, C.; Livingston, U.; Journal of Applied Physics, 1959, XXX (4), S120.

3. Guéron, S.; Deshmukh, M.; Myers, E.; Ralph, D., Physical Review Letters, 1999, LXXXIII (20), 4148.

4. Patel, S.; International Journal of Innovative Research in Science, Engineering and Technology, 2015, IV (8), 7556.

5. Ong, B.; Chee, E.; Abd Hamid, S.; Lim, K.; "Synthesis and characterization of nickel ferrite magnetic nanoparticles by coprecipitation method," In Proceedings of the AIP Conference, 2012, 221-229.

6. Sagadevan, S.; Chowdhury, Z.; Rafique, R.; Material Research, 2018, XXI (2).

7. Yin, H.; Too, H.P.; Chow, G.M.; Biomaterials, 2005, 26, 5818

8. Baldi, G.; Bonacchi, D.; Franchini, M.C.; Gentili, D.; Lorenzi, G.; Ricci, A.; et al., Langmuir, 2007, 23, 4026.

9. Beji, Z.; Hanini, A.; Smiri, L.S.; Gavard, J.; Kacem, K.; Villain, F.; et al, Chemistry of Materials, 2010, 22, 5420.

10. Tomitaka, A.; Hirukawa, A.; Yamada, T.; Morishita, S.; Takemura, Y.; J. Magnetism Magnet. Mater., 2009, 321, 1482.

11. Maxwell, J.C.; "Electricity and Magnetism", Oxfod University Press, New York, 1973, Vol. 2.

12. Koop, C. G.; Phys. Rev., 1951, 83, 121.

13. Robinin, L.T.; Novikova, Z.I.; "Ferrite", IZV Acad. Nouk USSR, Minisik, 1960.

14. Batoo, K.M.; Kumar, S.; Lee, C.G.; Alimuddin, Current Applied Physics, 2009, 9, 1072.

15. Patange, S.M.; Shirsath, S.E.; Lohar, K.S.; Jadhav, K.S.; Kulkarni, N.; Jadhav, K.M.; Physica B: Condensed Matter, 2011, CDVI (3), 663 